\title{
MONOKARYOTIC VARIATION AND HAPLOID SELECTION IN SCHIZOPHYLLUM COMMUNE
}

\author{
G. SIMCHEN \\ A.R.C. Unit of Biometrical Genetics, \\ Department of Genetics, The University, Birminghom, 15
}

Received 28.viii.65

\section{INTRODUCTION}

As in Collybia velutipes (Croft and Simchen, 1965), the sexual monokaryotic progeny of single dikaryotic isolates of Schizophyllum commune show a wide range of variation for growth rate and morphology, resulting presumably from the segregation of heterozygous loci. The studies reported here were aimed at exploiting this variation, which is controlled by a polygenic system. Generally, Schizophyllum is easier to handle than Collybia, and its life cycle is considerably shorter. The mating types of $S$. commune are simple to determine, and therefore linkage relationships between polygenic blocks affecting growth rate and the incompatibility factors can be readily examined.

Selection lines were initiated in order to fix the variation recovered among monokaryotic progeny of the wild isolates. From the progress of these selection experiments, it was hoped to understand better the polygenic system involved. The present system is, however, unusual in being haploid, hence neither dominance nor any other heterozygous interactions need be considered. It was therefore expected that the monokaryotic polygenic system would be simple to analyse, and the outcome of the haploid selection easy to interpret.

\section{MATERIALS AND METHODS}

Six dikaryons of $S$. commune were isolated from dry fruit bodies recently collected in the wild. Isolates I and 2 were obtained from fruit bodies collected in England, the details of which were given in a previous publication (Simchen and Jinks, 1964). Isolates $3,4,5$ and 6 were obtained from fruit bodies which were sent by Professor J. R. Raper, Harvard University. He collected them in well separated localities near Cambridge and Lexington, Massachusetts, U.S.A. All six fruit bodies were collected during November I963.

When received in the laboratory, the fruit bodies were left overnight on Petridishes containing $\mathrm{SC}$ medium to absorb water (for the compositions of the media $\mathrm{SC}, \mathrm{SF}$ and MT, see Simchen and Jinks (1964)). The non-hymenial tissue was then dissected, and dikaryotic mycelia were obtained after few days of growth in the incubator at $25^{\circ} \mathrm{C}$.

Dikaryons were fruited on Petri-dishes containing $15-25 \mathrm{ml}$. of SF medium, at $18^{\circ} \mathrm{C}$., under continuous illumination by "day-light " fluorescent tubes (80-1 00 lumen/sq. ft.). As soon as the fruit bodies developed, prints of basidiospores on dry Petri-dishes were obtained, and suspensions in "Tween 80 " were made. These were diluted and spread on MT medium (2 per cent. malt) so that each plate contained $30-50$ basidiospores. $36-48$ hours of incubation at $25^{\circ} \mathrm{C}$. gave rise to minute 
colonies which were easily isolated under the dissecting microscope, and were transferred to MT Petri-dishes at the rate of five colonies per plate.

Growth-rate was determined in growth tube experiments at $25^{\circ} \mathrm{C}$. on MT medium, as described by Simchen and Jinks (1964) and by Croft and Simchen (1965). Each experiment consisted of two randomised blocks, each block being confined to one shelf in the incubator. The growth of the fungus (in $\mathrm{mm}$.) over ten days is referred to henceforth as "Growth rate".

The mating types of monokaryons were determined following Papazian (1950). Testers representing the four major incompatibility groups (for each isolate) were mated with the unknown monokaryon on one Petri-dish, while the monokaryon itself was inoculated at the centre. Thus every plate gave the whole information about the mating type of one monokaryon, as well as its morphological features. The test was usually carried out on Complete medium (SC) or on Migration Complete medium (Snider and Raper, 1958). No further distinction was made between the two recombinant $A$ factors or the two recombinant $B$ factors (Raper, Baxter and Middleton, 1958). A more detailed account of the genetics of $S$. commune can be found in Raper and Miles (1958).

No common incompatibility factor was found between any of the six different isolates when all possible crosses between them were made. The mating types of the nuclei of the original dikaryons were determined by di-mon matings with their monokaryotic progeny, according to the method devised by Papazian (1950). These matings showed the dikaryons to be:

$$
\begin{aligned}
& \text { Isolate I }\left(A_{1} B_{1}+A_{2} B_{2}\right) \\
& \text { Isolate } 2\left(A_{3} B_{4}+A_{4} B_{3}\right) \\
& \text { Isolate } 3\left(A_{5} B_{5}+A_{6} B 6\right) \\
& \text { Isolate } 4\left(A_{7} B_{7}+A_{8} B 8\right) \\
& \text { Isolate } 5\left(A_{9} B_{1 \mathrm{O}}+A_{\mathrm{I}} B_{9}\right) \\
& \text { Isolate } 6\left(A_{\mathrm{I}} B_{\mathrm{I}} \mathrm{I}+A_{\mathrm{I}} B_{12}\right)
\end{aligned}
$$

The numbers designated to the incompatibility factors do not correspond to numbers of mating types originated from Professor Raper's collection in Harvard University.

\section{NATURAL VARIATION AMONG PROGENY OF SINGLE ISOLATES}

\section{(i) The experiments}

\begin{tabular}{|c|c|c|c|c|c|c|}
\hline \multirow{2}{*}{ Parental Dikaryon } & \multicolumn{2}{|c|}{ Error } & \multicolumn{2}{|c|}{ Between blocks } & \multicolumn{2}{|c|}{ Between progeny } \\
\hline & d.f. & M.S. & d.f. & M.S. & d.f. & M.S. \\
\hline $\begin{array}{l}\text { Isolate I } \\
\text { Isolate } 2(a) \\
\text { Isolate } 2(b) \\
\text { Isolate } 3 \\
\text { Isolate } 4 \\
\text { Isolate } 5 \\
\text { Isolate } 6\end{array}$ & $\begin{array}{r}115 \\
58 \\
94 \\
98 \\
73 \\
99 \\
99\end{array}$ & $\begin{array}{r}4 \cdot 63 \\
I I \cdot 31 \\
2 \cdot 58 \\
9 \cdot 74 \\
19 \cdot 61 \\
4 \cdot 88 \\
34 \cdot 44\end{array}$ & $\begin{array}{l}\text { I } \\
\text { I } \\
\text { I } \\
\text { I } \\
\text { I } \\
\text { I } \\
\text { I }\end{array}$ & $\begin{array}{c}2 \cdot 09 \\
4 \cdot 4^{8} \\
12 \cdot 13^{*} \\
186 \cdot 18^{* * *} \\
138 \cdot 17^{* * *} \\
3 \cdot 3^{8} \\
5 \cdot 44\end{array}$ & $\begin{array}{r}115 \\
58 \\
94 \\
98 \\
73 \\
99 \\
99\end{array}$ & $\begin{array}{l}80 \cdot 26^{* * *} \\
62 \cdot 00^{* * *} \\
67 \cdot 8^{* * *} \\
52 \cdot 75^{* * *} \\
48 \cdot 16^{* * *} \\
61 \cdot 71^{* * *} \\
79 \cdot 98^{* * *}\end{array}$ \\
\hline
\end{tabular}

Monokaryotic progeny of each of the six isolates were grown in separate experiments. One of the original dikaryons, that is isolate 2, was used to start the selection experiment reported later; it has

TABLE I

Analyses of variance of the growth rates of monokaryotic progenies 
provided two independent samples of monokaryotic progeny, one in the beginning of the selection and the other after the gth generation of progeny. These two samples are marked $(a)$ and $(b)$ respectively. Table I contains the analyses of variance, each row representing progeny of a single wild isolate grown in a separate experiment. Two of the experiments are also given in the form of frequency diagrams (fig. I).
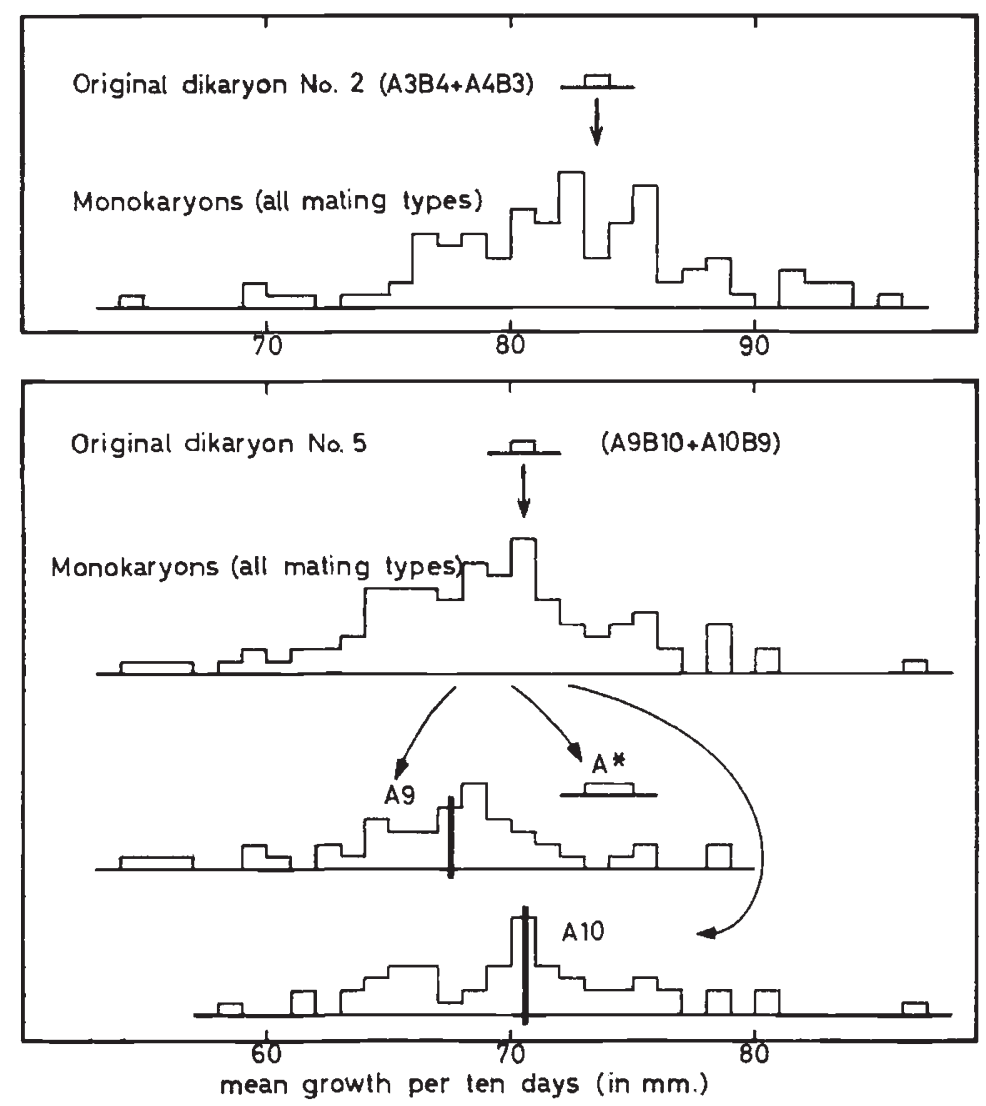

FIG. 1.-Growth rate distributions of two wild isolates and their monokaryotic progenies. The progeny of isolate 2 presented here are referred to in the text as experiment $2(b)$. The distribution of the progeny of isolate 5 is subdivided according to the $A$ incompatibility factor, to which a polygenic block controlling growth rate was found to be linked. The difference between the means of $A 9$ and AIO (marked by bars) is significant, as shown by the linkage analysis of variance (see table 3 ).

(ii) Estimation of the components of variation and the number of effective factors

The expectations of the mean squares in the analysis of variance are the same as those given by Croft and Simchen (1965): $\sigma_{E}^{2}$ for error (blocks $\times$ progeny interaction) and $\sigma_{E}^{2}+2 \sigma_{G}^{2}$ for the between progeny item. The components of variation are accordingly: $V_{E}=\hat{\sigma}_{E}^{2}$ (error component), $V_{G}=\hat{\sigma}_{G}^{2}$ (genetic component), where $V_{T}($ total variation $)=V_{E}+V_{G}$. These estimates are given in table 2. 
The number of effective factors was estimated using the second method described by Croft and Simchen, in which the progeny with the extreme phenotypes were regarded as containing the effective factors in the associated phase, all the + factors in one extreme and

TABLE 2

Components of variation ( $V_{E}=$ error, $V_{G}=$ genetic variation), and number of effective factors $(k)$, estimated from the analysis of variance

\begin{tabular}{|c|c|c|c|c|c|}
\hline \multirow{2}{*}{$\begin{array}{l}\text { Parental } \\
\text { dikaryon }\end{array}$} & \multirow{2}{*}{$\begin{array}{l}\text { No. of } \\
\text { progeny }\end{array}$} & \multicolumn{2}{|c|}{ Components of variation } & \multicolumn{2}{|c|}{ No. effective factors } \\
\hline & & $V_{E}$ & $V_{G}$ & Range $=\widehat{2 k d}$ & $\hat{k}$ \\
\hline $\begin{array}{l}\text { Isolate } 1 \\
\text { Isolate } 2(a) \\
\text { Isolate } 2(b) \\
\text { Isolate } 3 \\
\text { Isolate } 4 \\
\text { Isolate } 5 \\
\text { Isolate } 6\end{array}$ & $\begin{array}{r}116 \\
59 \\
95 \\
99 \\
74 \\
\text { I00 } \\
\text { I00 }\end{array}$ & $\begin{array}{r}4 \cdot 625 \\
\cdot 311 \\
-584 \\
9 \cdot 743 \\
19 \cdot 607 \\
4 \cdot 875 \\
34 \cdot 435\end{array}$ & $\begin{array}{l}37 \cdot 817 \\
25 \cdot 345 \\
32 \cdot 400 \\
21 \cdot 503 \\
14 \cdot 275 \\
28 \cdot 417 \\
22 \cdot 774\end{array}$ & $\begin{array}{l}36 \cdot 50 \\
27 \cdot 00 \\
31 \cdot 50 \\
24 \cdot 00 \\
26 \cdot 00 \\
31 \cdot 50 \\
30 \cdot 00\end{array}$ & $\begin{array}{r}8.807 \\
7.191 \\
7.656 \\
6.697 \\
11.839 \\
9.292 \\
9.880\end{array}$ \\
\hline
\end{tabular}

all the - factors in the other. The range of the progeny is therefore an estimate of $2 k d$ ( $k$ is the number of effective factors, and $d$ is the average effect of these factors), and the genetic variance (or the heritable component of variation, $\left.V_{G}\right)$ is $k \widehat{d}^{2}$. Therefore,

$$
\hat{k}=\frac{1}{4} \frac{\text { (range of progeny) }}{{ }^{2}}
$$

The estimates of $k$, together with the ranges of progeny, are also included in table 2.

\section{(iii) Linkage to the incompatibility factors}

Since all progeny (except two-thirds of the progeny of isolate $\mathrm{I}$ ) were tested for their mating types, further comparisons in the analysis of variance could be made between the growth rates of the different mating type groups. If we assume that the incompatibility factors themselves have no effect on the growth a of monokaryotic mycelium, then any significant difference in such comparisons can be regarded as evidence for close linkage between polygenic blocks and the incompatibility factors. Some evidence confirming this assumption can be found in the selection experiments, in which the same polygenic block has apparently been linked to two allelic incompatibility factors. For each set of progeny, the few monokaryons with recombinant incompatibility factors were excluded from the analysis, and for the remainder two comparisons were made: (i) between the two $A$ factors (I d.f.), (ii) between the two $B$ factors ( 1 d.f.). The mean squares obtained from these two comparisons were tested against the 
"genetic remainder" mean squares (this is in fact the remainder of the "between progeny" sum of squares divided by the appropriate number of d.f.) by the usual $\mathrm{F}$ test. The results of these " linkage tests" are summarised in table 3 .

If we have $n$ progeny in each of the four mating type groups, and 2 observations for each progeny, then the expected mean squares are:

$\begin{array}{ll}\text { Linkage to } A & \sigma_{E}^{2}+2 \sigma_{R}^{2}+4 n \sigma_{L A}^{2} \\ \text { Linkage to } B & \sigma_{E}^{2}+2 \sigma_{R}^{2}+4 n \sigma_{L B}^{2} \\ \text { Genetic remainder } & \sigma_{E}^{2}+2 \sigma_{R}^{2} \\ \text { Error } & \sigma_{E}^{2}\end{array}$

In the experiments analysed here, however, the four mating type groups were not exactly equal (although not significantly different

TABLE 3

Analyses of variance for linkage of polygenic blocks affecting growth rate to the incompatibility factors

\begin{tabular}{|c|c|c|c|c|c|c|c|c|}
\hline \multirow{2}{*}{$\begin{array}{l}\text { Parental } \\
\text { Dikaryon }\end{array}$} & \multirow{2}{*}{$\begin{array}{l}\text { No. of progeny with } \\
\text { non-recombinant } \\
\text { factors }\end{array}$} & \multicolumn{2}{|c|}{$\begin{array}{l}\text { Linkage to } A \\
\text { (I d.f.) }\end{array}$} & \multicolumn{2}{|c|}{$\begin{array}{l}\text { Linkage to } B \\
\text { (I d.f.) }\end{array}$} & \multicolumn{2}{|c|}{$\begin{array}{l}\text { Genetic } \\
\text { remainder }\end{array}$} & \multirow{2}{*}{ Notes } \\
\hline & & M.S. & $\hat{\sigma}_{L A}^{2}$ & M.S. & $\hat{\sigma}_{L B}^{2}$ & d.f. & M.S. & \\
\hline $\begin{array}{l}\text { Isolate : } \\
\text { Isolate } 2(a) \\
\text { Isolate } 2(b) \\
\text { Isolate } 3 \\
\text { Isolate } 4 \\
\text { Isolate } 5 \\
\text { Isolate } 6\end{array}$ & $\begin{array}{l}39 \dagger \\
59 \\
92 \\
98 \\
71 \\
98 \\
97\end{array}$ & $\begin{array}{c}55 \cdot 66 \\
19 \cdot 60 \\
98 \cdot 65 \\
204 \cdot 08^{*} \\
2 \cdot 04 \\
485 \cdot 16^{* *} \\
460 \cdot 21^{* *}\end{array}$ & $\begin{array}{l}0 \cdot 0 \\
1 \cdot 097 \\
0 \cdot 33^{8} \\
1 \cdot 55^{2} \\
0 \cdot 0 \\
4 \cdot 380 \\
3 \cdot 962\end{array}$ & $\begin{array}{r}180 \cdot 54 \\
151 \cdot 10 \\
89 \cdot 35 \\
2 \cdot 58 \\
26 \cdot 54 \\
42 \cdot 50 \\
0 \cdot 51\end{array}$ & $\begin{array}{l}2 \cdot 859 \\
1 \cdot 065 \\
0 \cdot 238 \\
0 \cdot 0 \\
0 \cdot 0 \\
0 \cdot 0 \\
0 \cdot 0\end{array}$ & $\begin{array}{l}36 \\
56 \\
89 \\
95 \\
68 \\
95 \\
94\end{array}$ & $\begin{array}{l}85 \cdot 54 \\
57 \cdot 11 \\
67 \cdot 58 \\
52 \cdot 00 \\
42 \cdot 57 \\
57 \cdot 58 \\
79 \cdot 45\end{array}$ & $\begin{array}{l}A_{5}>A 6 \\
A_{10}>A 9 \\
A_{12}>A 11\end{array}$ \\
\hline
\end{tabular}

$\dagger$ The mating types were determined only for 39 out of the 116 progeny of isolate 1 .

- Significant at $0 \cdot 05$.

** Significant at 0.025-0.001.

from $I: I: I: I)$ and $2 n$ was therefore substituted by adjusted values calculated after Snedecor (1956, pp. 269-270) for unequal groups in the analysis of variance. The estimates of the linkage components of variation calculated from the above analysis $\left(\hat{\sigma}_{L A}^{2}\right.$ and $\left.\hat{\sigma}_{L B}^{2}\right)$ are also included in table 3 .

\section{SELECTION AMONG PROGENY OF ISOLATE 2}

(i) The experiments

The 59 progeny of isolate 2 (experiment $(a)$ ) were chosen as the generation from which to start the selection. Two compatible monokaryons with high growth rate were mated and the resulting dikaryon was fruited under the conditions described earlier. The monokaryotic progeny provided the second generation of progeny in the selection line $H_{1}$, designated the $H_{1.2}$ generation. Similarly, the $H_{2}$ selection line was initiated, having one parental monokaryon in common with 
246

G. SIMCHEN

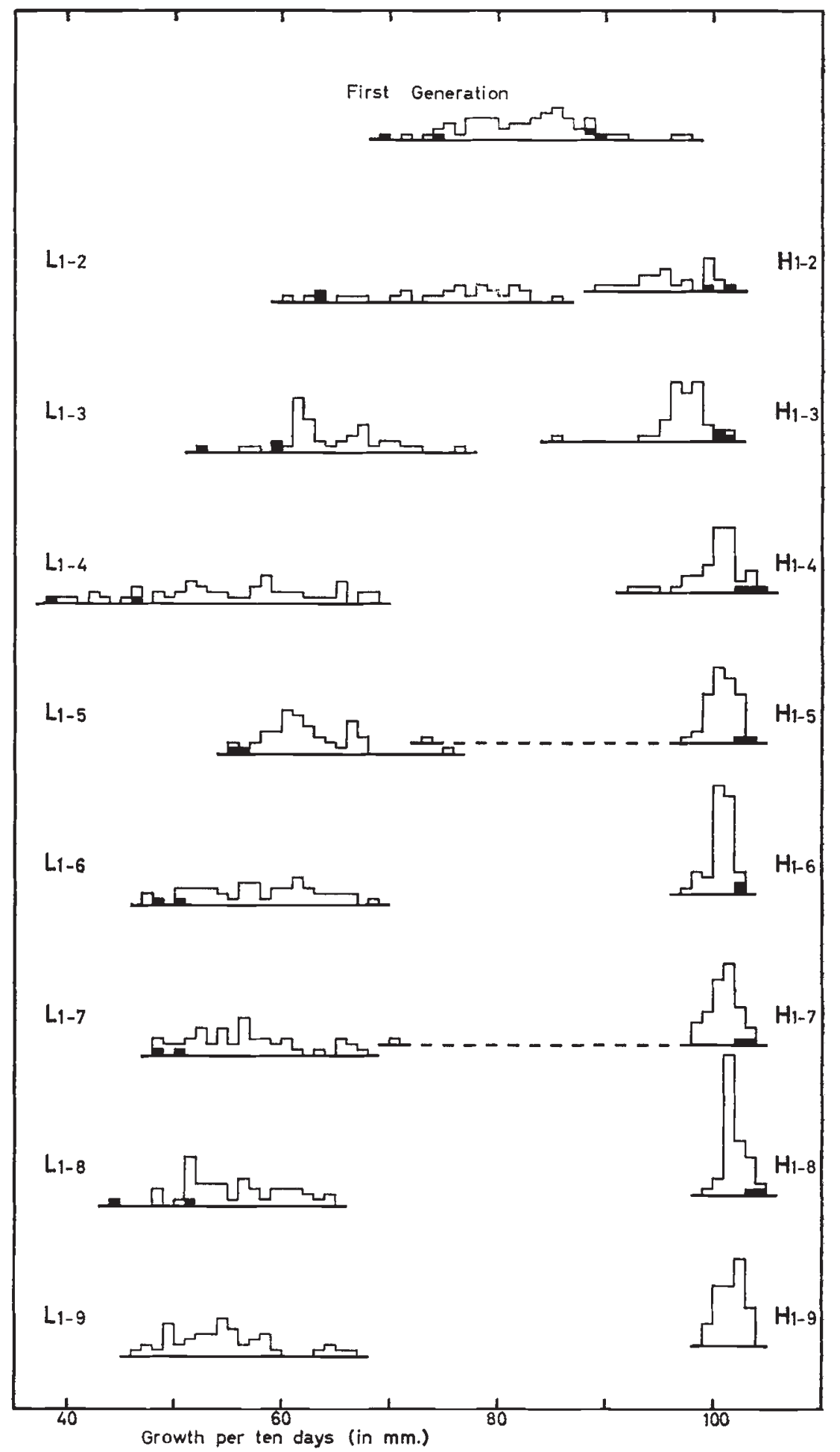

Fig. 2. -Frequency distributions of the selection experiments $L_{1}$ and $H_{1}$. The monokaryons which were chosen as parents of subsequent generations are blocked. "Deviants" are connected to the distributions by broken lines. 
$H_{1}$. The two lines in which low growth rates were selected for were designated $L_{1}$ and $\mathrm{L}_{2}$, and they had also one of the parental monokaryons in common. For each generation of monokaryons, the growth rates were determined in a growth tube experiment. The fastest compatible monokaryons in each of the $H$ selections, and the slowest monokaryons in each of the $L$ selections were chosen as the parents of the following generation. In generations 2, 3 and 4 the mating types of the selected monokaryons were not determined, and all compatible matings among them provided a common suspension of basidiospores, from which the following generation was sampled. The number of selected monokaryons varied therefore between 2 and 4 as indicated in figs. 2 and 3. From the $5^{\text {th }}$ generation onwards, the mating types of the extreme monokaryotic lines were determined and only one compatible mating between non-recombinant mating types provided the subsequent generation.

It was noticed, however, that a recombinant $B$ established itself in $H_{1}$ during the uncontrolled stage of the selection (in generation 4), and a recombinant $A$ was selected in $H_{2-6}$ because it took part in the only possible matings among the $I_{5}$ fastest monokaryons. Hence crosses following $H_{1-4}$ were either $A_{3} B^{*} \times A_{4} B_{4}$ or $A_{3} B_{4} \times A_{4} B^{*}$, and following $H_{2-6}$ either $A_{3} B_{3} \times A^{*} B_{4}$ or $A_{3} B_{4} \times A^{*} B_{3}$.

All four selection lines of generation 2 were grown together in one experiment, hence the small samples of progeny-25 to 30 for each selection line (see tables 4 and 5 ). After generation 2, $L_{1}$ was grown and randomised together with $H_{1}$, while $L_{2}$ was grown together with $\mathrm{H}_{2}$; each generation contained about 50 progeny per selection line. The fluctuations in the number of progeny were largely caused by the elimination of progeny in which one duplicate was missing, and of progeny which turned out to be dikaryons or common- $A$ heterokaryons.

The selected lines from each generation were kept in stock bottles at $5^{\circ} \mathrm{C}$., and all of them were grown together in one experiment after the 9 th generation, thus making it possible to compare the different generations in a common environment. This was done in order to overcome the problem of different generations being assessed under slightly different experimental conditions arising from different batches of medium, different shelves in the incubator, etc. The relations between the frequency diagrams of different generations given in figs. 2 and 3 are based upon this final comparative experiment; in fact only the selected monokaryons of the $H$ selections were used for these figures, since the error components in the $L$ selection lines were found to be very large, and the agreement between duplicates not as satisfactory as between duplicates of the $H$ monokaryons.

Another way of representing results of a selection is by a graph of the total response $v s$. the accumulation of the selection differential. To overcome the fluctuations in mean growth rates between experiments, the difference between the means of the two sets of progenies grown in the same experiment $\left(H_{1}\right.$ and $L_{1}$ or $H_{2}$ and $\left.L_{2}\right)$ was taken 
$24^{8}$

G. SIMCHEN

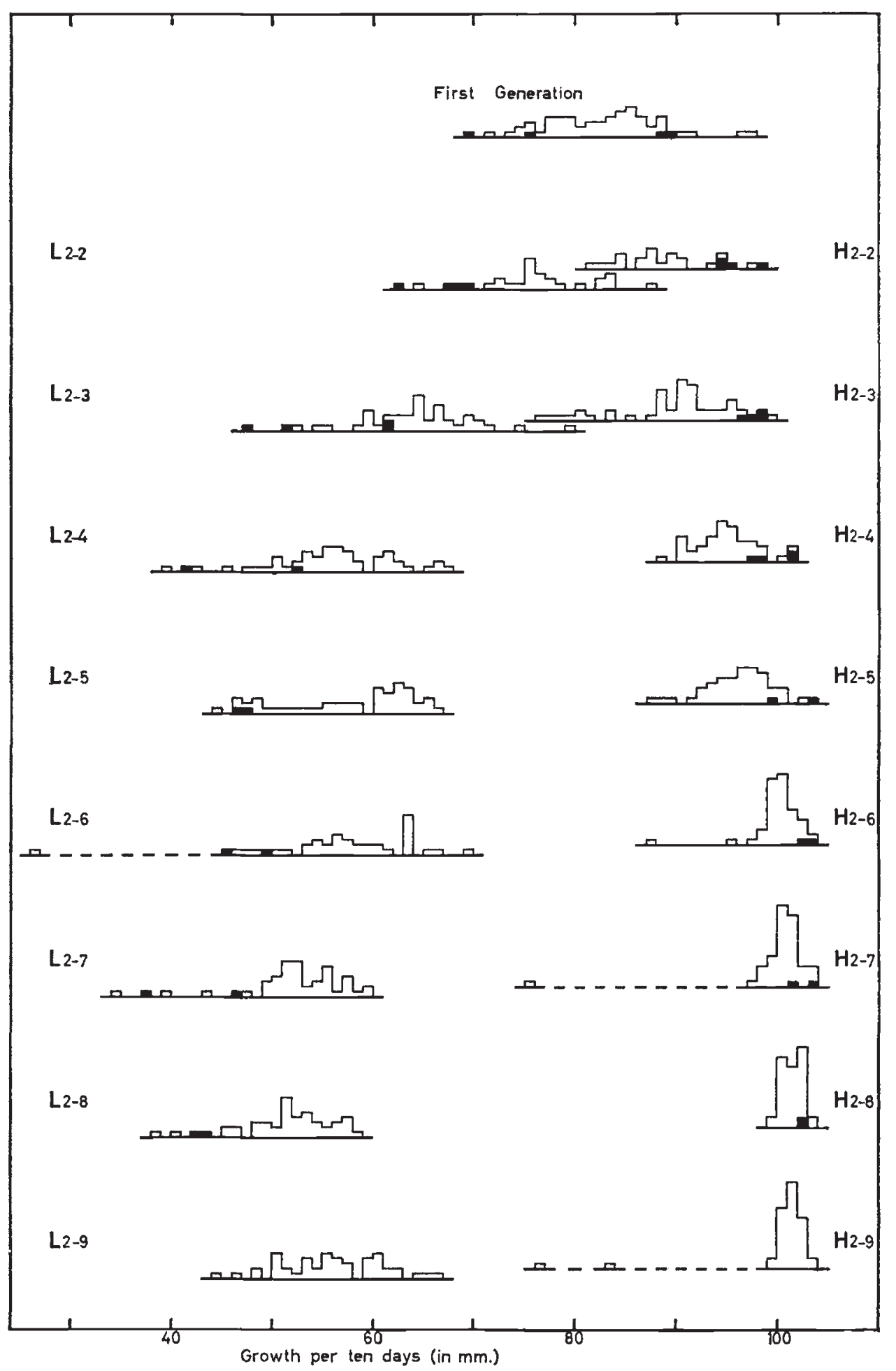

Fra. 3-Frequency distributions of the selection experiments $L_{2}$ and $H_{2}$. The monokaryons which were chosen as parents of subsequent generations are blocked. "Deviants" are connected to the distributions by broken lines. 
as response, and the accumulated differentials of both selection lines up to the previous generation were similarly pooled. Fig. 4 shows the progress of selection when plotted in this way. A steady, almost linear, response was observed in generations 2, 3 and 4 , while later

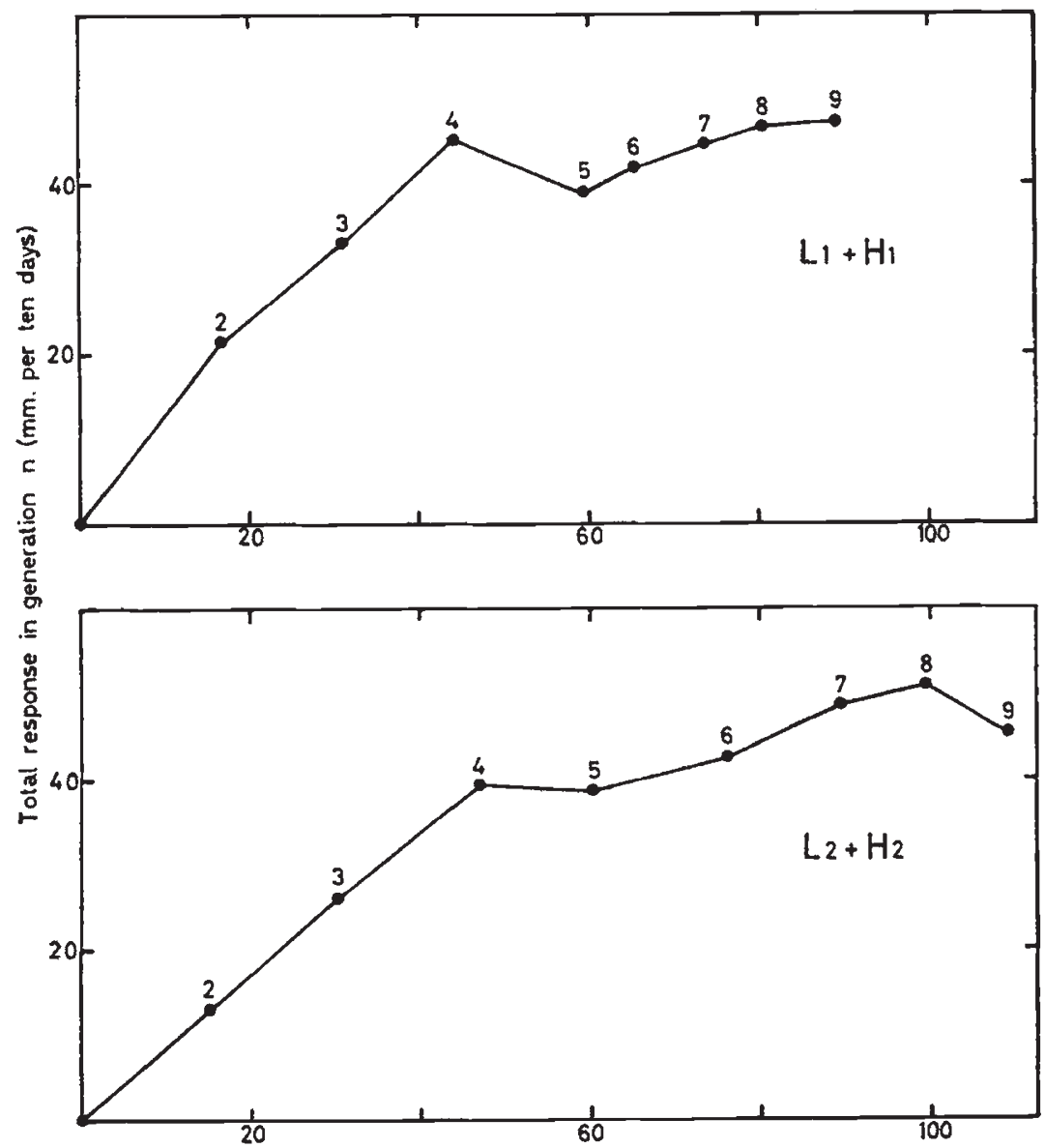

Accumulated selection differential in generation $n-1$ ( $\mathrm{mm}$. per ten days)

FIG. 4.- The selection experiments plotted on graphs which show the total response vs. the accumulated differential. The figures on the curve indicate the generation number. The occasional "deviants" were not included in the calculations.

generations showed very little progress. This is rather surprising considering the high level of genetic variation $\left(V_{G}\right)$ in both $L$ selections (see fig. 5).

\section{(ii) Changes in variation}

An analysis of variance of the growth rates of the progeny of each selection line in each generation was carried out. All the analyses are summarised in tables 4 and 5 . The estimates of the components of variation, $V_{E}$ and $V_{G}$, were calculated as before, and were plotted 
in fig. 5. The changes in the magnitude of $V_{G}$ should reflect the progress of the selection. One expects $V_{G}$ to decrease rapidly since the rate of inbreeding is very high; it is equivalent to selfing superimposed by assortative mating. Fig. 5 shows that contrary to expectations, the values of $V_{G}$ in $L_{1}$ and $L_{2}$ did not decrease during the course of the experiments, while in $H_{1}$ and $H_{2}$ they behaved as expected and achieved homozygosity in the $5^{\text {th }}$ and 7 th generations respectively.

TABLE 4

Analyses of variance of separate generations in selections $L_{1}$ and $H_{1}$

\begin{tabular}{|c|c|c|c|c|c|c|}
\hline \multirow{2}{*}{ Generation } & \multicolumn{2}{|c|}{ Between lines } & \multicolumn{2}{|c|}{ Between blocks } & \multicolumn{2}{|c|}{ Error } \\
\hline & d.f. & M.S. & d.f. & M.S. & d.f. & M.S. \\
\hline $\begin{array}{l}L_{1-2} \\
L_{1-3} \\
L_{1-4} \\
L_{1-5} \\
L_{1-6} \\
L_{1-7} \\
L_{1-8} \\
L_{1-8}\end{array}$ & $\begin{array}{l}29 \\
42 \\
52 \\
48 \\
49 \\
49 \\
49 \\
49\end{array}$ & $\begin{array}{r}93 \cdot 32^{* * *} \\
43 \cdot 57^{* *} \\
126 \cdot 0^{* * *} \\
27 \cdot 90^{* * *} \\
58 \cdot 73^{* * *} \\
51 \cdot 86^{* *} \\
43 \cdot 3^{* * *} \\
44 \cdot 98^{* * *}\end{array}$ & $\begin{array}{l}I \\
I \\
I \\
I \\
I \\
I \\
I \\
I \\
I\end{array}$ & $\begin{array}{l}5 \cdot 40 \\
74 \cdot 42^{*} \\
37 \cdot 44^{*} \\
63 \cdot 68^{* * *} \\
\text { I.21 } \\
23 \cdot 04 \\
9 \cdot 00 \\
20 \cdot 25\end{array}$ & $\begin{array}{l}29 \\
42 \\
52 \\
48 \\
49 \\
49 \\
49 \\
49\end{array}$ & $\begin{array}{r}3 \cdot 78 \\
14.06 \\
8 \cdot 31 \\
3 \cdot 52 \\
4.92 \\
7 \cdot 24 \\
7 \cdot 92 \\
7 \cdot 37\end{array}$ \\
\hline $\begin{array}{l}H_{1-2} \\
H_{1-3} \\
H_{1-4} \\
H_{1-5} \\
\dagger \dagger \\
H_{1-6} \\
H_{1-7} \\
{ }_{\dagger} \\
H_{1-8} \\
H_{1-9}\end{array}$ & $\begin{array}{l}25 \\
44 \\
45 \\
47 \\
48 \\
49 \\
46 \\
47 \\
48 \\
48\end{array}$ & $\begin{array}{c}22 \cdot 52^{* * *} \\
12 \cdot 24^{* * *} \\
12 \cdot 10^{* * *} \\
3 \cdot 01 \\
35 \cdot 17^{* * *} \\
2 \cdot 50 \\
3 \cdot 21^{*} \\
41 \cdot 12^{* * *} \\
1 \cdot 90 \\
3 \cdot 09\end{array}$ & $\begin{array}{l}I \\
I \\
I \\
I \\
I \\
I \\
I \\
I \\
I \\
I \\
I\end{array}$ & 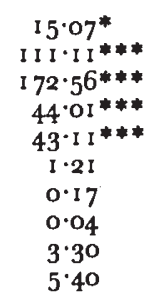 & $\begin{array}{l}25 \\
44 \\
45 \\
47 \\
48 \\
49 \\
46 \\
47 \\
48 \\
48\end{array}$ & $\begin{array}{l}2 \cdot 60 \\
3 \cdot 00 \\
2 \cdot 03 \\
2 \cdot 56 \\
2 \cdot 53 \\
2 \cdot 33 \\
1.67 \\
1.68 \\
1.83 \\
2 \cdot 04\end{array}$ \\
\hline
\end{tabular}

*** Significance of 0.001 * Significance of $0.05^{-0} 0.01$.

$\dagger \dagger$ Alternative analysis, including the "deviants".

The values of $V_{E}$ were also plotted in fig. 5 since they are related to some extent to the $V_{G}$ estimates. All the $V_{E}$ estimates for the $L$ selections were higher than the corresponding estimates in the $H$ selections, although grown in the same experiments. When an $\mathbf{F}$ test was applied to each of these 16 pairs of estimates, the ratio $V_{E} L / V_{E} H$ was found to be significantly higher than $\mathrm{I} \cdot \mathrm{O}$ in $\mathrm{I}$ I comparisons.

\section{(iii) Unilateral dikaryotisation and the appearance of " deviants"}

The duplicate selection lines behaved remarkably alike throughout the experiments. The two $H$ selections reached the same mean growth rates (and homozygosity), while the differences between the two $L$ selection lines were only slight.

The $L_{2}$ selection developed unusual and non-characteristic features of mating: most monokaryons of this line, when mated with another 
compatible monokaryon, behaved as donors of nuclei only-that is unilateral dikaryotisation of the other mycelium occurred long before dikaryotisation of the $L_{2}$ mycelium. When two compatible $L_{2}$ monokaryons were mated, it took a long time (sometimes up to a week) for the dikaryotic mycelium to appear, and after appearing it grew only in patches. This phenomenon is similar to the one described by Papazian (195I). The heritable nature of the unilaterality was

TABLE 5

Analyses of variance of separate generations in selections $L_{2}$ and $H_{2}$

\begin{tabular}{|c|c|c|c|c|c|c|}
\hline \multirow{2}{*}{ Generation } & \multicolumn{2}{|c|}{ Between lines } & \multicolumn{2}{|c|}{ Between blocks } & \multicolumn{2}{|c|}{ Error } \\
\hline & d.f. & M.S. & d.f. & M.S. & d.f. & M.S. \\
\hline $\begin{array}{l}L_{2-2} \\
L_{2-3} \\
L_{2-4} \\
L_{2-5} \\
L_{2-8} \\
\dagger \dagger \\
L_{2-8} \\
L_{2-8} \\
L_{2-9}\end{array}$ & $\begin{array}{l}28 \\
44 \\
49 \\
49 \\
38 \\
39 \\
45 \\
45 \\
45\end{array}$ & $\begin{array}{r}68 \cdot 9 I^{* * *} \\
70 \cdot 15^{* * *} \\
77 \cdot 33^{* * *} \\
8 \mathrm{I} \cdot 4^{* * *} \\
67 \cdot 99^{* * *} \\
114 \cdot 06^{* * *} \\
53 \cdot 80^{* * *} \\
4 \mathrm{I} \cdot 87^{* * *} \\
5 \mathrm{I} \cdot 80^{* * *}\end{array}$ & $\begin{array}{l}\text { I } \\
\text { I } \\
\text { I } \\
\text { I } \\
\text { I } \\
\text { I } \\
\text { I } \\
\text { I } \\
\text { I }\end{array}$ & $\begin{array}{c}3.3^{8} \\
23.51 \\
\text { I } 14.49^{* * *} \\
\text { 1 } 3.69^{*} \\
3.28 \\
3.20 \\
0.00 \\
3.52 \\
3.14\end{array}$ & $\begin{array}{l}28 \\
44 \\
49 \\
49 \\
38 \\
39 \\
45 \\
45 \\
45\end{array}$ & $\begin{array}{r}6 \cdot 59 \\
12 \cdot 56 \\
4 \cdot 67 \\
2 \cdot 71 \\
7 \cdot 23 \\
7 \cdot 05 \\
4.09 \\
6 \cdot 37 \\
11 \cdot 61\end{array}$ \\
\hline $\begin{array}{c}H_{2-2} \\
H_{2-3} \\
H_{2-4} \\
H_{2-5} \\
H_{2-6} \\
H_{2-7} \\
+\dagger \\
H_{2-8} \\
H_{2-8} \\
+\dagger\end{array}$ & $\begin{array}{l}24 \\
49 \\
45 \\
48 \\
46 \\
48 \\
49 \\
47 \\
42 \\
44\end{array}$ & $\begin{array}{c}45 \cdot 29^{* * *} \\
62 \cdot 2^{* * *} \\
19 \cdot 28^{* * *} \\
21 \cdot 34^{* * *} \\
11 \cdot 79^{* * *} \\
3 \cdot 88 \\
3^{2} \cdot 00^{* * *} \\
2 \cdot 62^{*} \\
1 \cdot 79 \\
43 \cdot 76^{* * *}\end{array}$ & $\begin{array}{l}\text { I } \\
\text { I } \\
\text { I } \\
\text { I } \\
\text { I } \\
\text { I } \\
\text { I } \\
\text { I } \\
\text { I } \\
\text { I }\end{array}$ & $\begin{array}{c}3 \cdot 38 \\
68 \cdot 89^{* * *} \\
71 \cdot 3^{* * *} \\
18 \cdot 00^{* *} \\
53 \cdot 63^{* * *} \\
6 \cdot 3^{8} \\
6 \cdot 76 \\
0 \cdot 51 \\
0 \cdot 94 \\
2 \cdot 50\end{array}$ & $\begin{array}{l}24 \\
49 \\
45 \\
48 \\
46 \\
48 \\
49 \\
47 \\
42 \\
44\end{array}$ & $\begin{array}{l}1.09 \\
4.56 \\
3.98 \\
1.88 \\
1.37 \\
3.63 \\
3.56 \\
1.57 \\
3.44 \\
8.07\end{array}$ \\
\hline
\end{tabular}

*** Significance of 0.001 . ** Significance of $0.01-0.001$

* Significance of $0.05-0 \cdot 01$. $† \dagger$ Alternative analysis, including the "deviants".

demonstrated in crosses between $L_{2}$ and the other selection lines, where some of the progeny behaved similarly to $L_{2}$ monokaryons, and showed unilateral dikaryotisation in matings.

Another phenomenon which has not been previously mentioned, is the appearance of " deviants", that is monokaryons with a distinctly lower growth rate than the other members of the same generation of progeny, as seen in figs. 2 and 3. Contamination is not an acceptable explanation since all "deviants" were found to carry the appropriate incompatibility factors, and they were all outside the range of growth rates of monokaryons in use at the same time. Mutations or rare (unequal) cross-over events could be possible explanations, but these "deviants" were not analysed further. Inclusion of the deviants in the data provided alternative analyses and alternative estimates of the components of variation (see tables 4 and 5 , and fig. 5). 

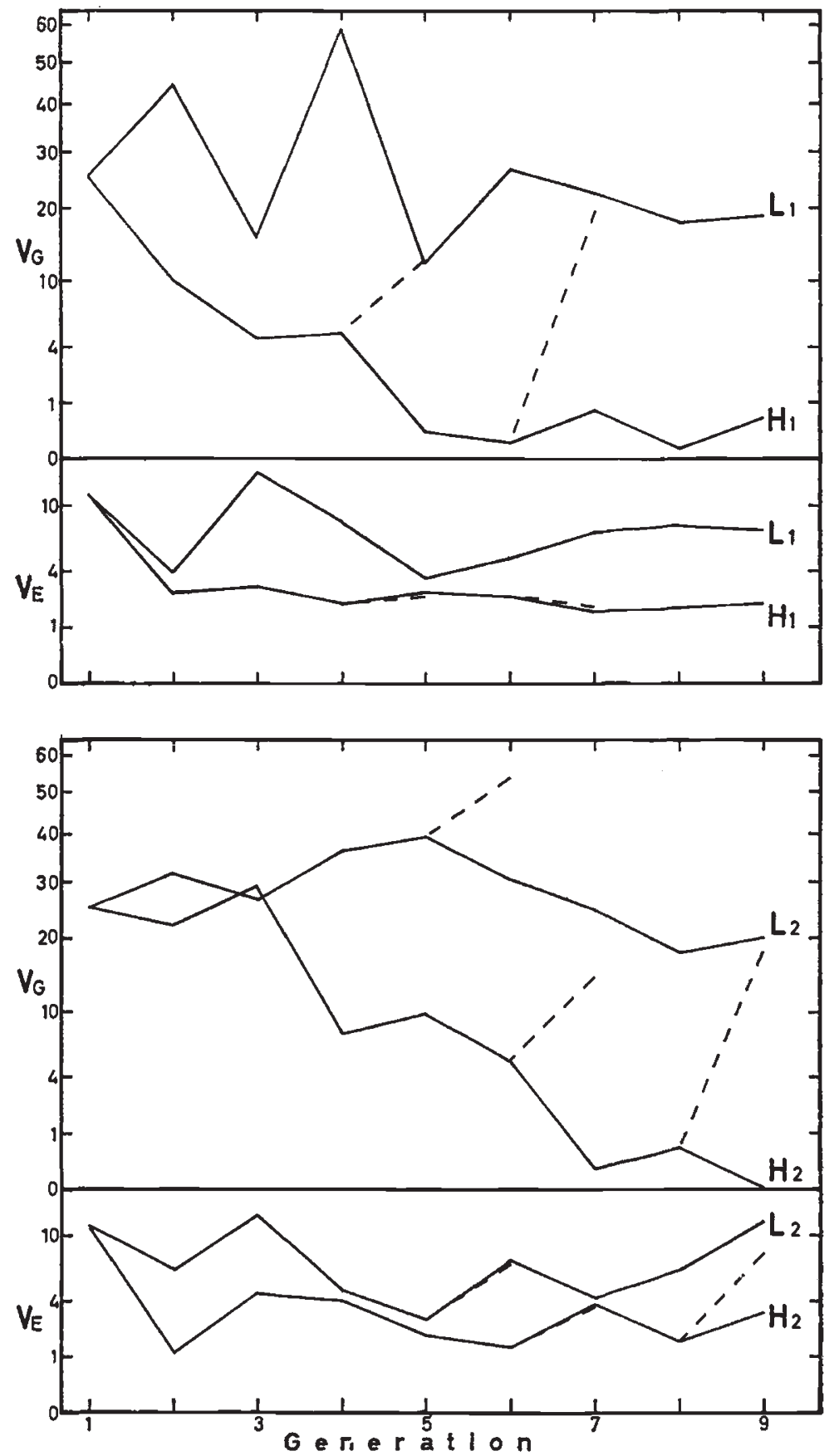

Frc. 5. - The changes occurring in the components of variation during the course of the selection. $V_{G}$ is the estimate of the heritable component and $V_{E}$ is the estimate of the environmental component of variation. The broken lines take into account the "deviants". 


\section{CROSSES BETWEEN SELECTION LINES}

(i) The experiments

Crosses were made between monokaryons representing the selection lines described in the previous section. The generations from which the monokaryons were chosen were $L_{1-9}, H_{1-9}, L_{2-8}, H_{2-8}$. Slight complications which arose during the planning of these crosses were the restrictions imposed by the incompatibility system, and the heritable variation within the $L$ selection lines. It was also desired to retest the relationships between the polygenic systems controlling growth rate and the incompatibility factors, and to detect recombinants within these factors. Therefore recombinant incompatibility factors were not used for the crosses, despite their presence in the two $H$ selections.

TABLE 6

Analyses of variance of progeny of crosses between selection lines

\begin{tabular}{|c|c|c|c|c|c|c|c|}
\hline \multicolumn{2}{|c|}{ Parents } & \multicolumn{2}{|c|}{ Error } & \multicolumn{2}{|c|}{ Between blocks } & \multicolumn{2}{|c|}{ Between progeny } \\
\hline Monokaryons & $\begin{array}{c}\text { Selection } \\
\text { lines }\end{array}$ & d.f. & M.S. & d.f. & M.S. & d.f. & M.S. \\
\hline $\begin{array}{l}7444 \times 7454 \\
7418 \times 7664 \\
7649 \times 7454 \\
7647 \times 7664\end{array}$ & $\begin{array}{l}L_{1} \times H_{1} \\
L_{1} \times H_{2} \\
L_{2} \times H_{1} \\
L_{2} \times H_{2}\end{array}$ & $\begin{array}{l}99 \\
98 \\
99 \\
98\end{array}$ & $\begin{array}{r}5 \cdot 72 \\
4.91 \\
12.33 \\
13.85\end{array}$ & $\begin{array}{l}\text { I } \\
\text { I } \\
\text { I } \\
\text { I }\end{array}$ & $\begin{array}{c}0 \cdot 72 \\
47 \cdot 54^{* *} \\
322 \cdot 58^{* * *} \\
73.95^{*}\end{array}$ & $\begin{array}{l}99 \\
98 \\
99 \\
98\end{array}$ & $\begin{array}{r}85 \cdot 60^{* * *} \\
128 \cdot 31 * * * \\
252 \cdot 22 * * * \\
342 \cdot 41 * * *\end{array}$ \\
\hline $\begin{array}{l}7444 \times 7647 \\
7454 \times 7664\end{array}$ & $\begin{array}{c}L_{1} \times L_{2} \\
H_{1} \times H_{2} \\
\quad \dagger \dagger\end{array}$ & $\begin{array}{l}48 \\
48 \\
49\end{array}$ & $\begin{array}{l}7.60 \\
147 \\
\text { I } 49\end{array}$ & $\begin{array}{l}\text { I } \\
\text { I } \\
\text { I }\end{array}$ & $\begin{array}{l}9.80 \\
0.82 \\
0.49\end{array}$ & $\begin{array}{l}48 \\
48 \\
49\end{array}$ & $\begin{array}{r}\text { IOI } 75^{* * *} \\
\text { I } 4 \cdot 11 * * \\
3^{8} \cdot 3^{*} 1^{* * *}\end{array}$ \\
\hline $\begin{array}{l}7418 \times 7444 \\
7647 \times 7649\end{array}$ & $\begin{array}{l}L_{1} \times L_{1} \\
L_{2} \times L_{2}\end{array}$ & $\begin{array}{l}48 \\
45\end{array}$ & $\begin{array}{l}10 \cdot 77 \\
\text { II.61 }\end{array}$ & $\begin{array}{l}I \\
I\end{array}$ & $\begin{array}{l}8 \cdot 58 \\
3 \cdot 14\end{array}$ & $\begin{array}{l}48 \\
45\end{array}$ & $\begin{array}{l}51 \cdot 47^{* * * *} \\
5 I \cdot 80^{* * *}\end{array}$ \\
\hline
\end{tabular}

$\dagger \dagger$ Alternative analysis including a "deviant".

*** $\mathrm{P}<0.001 . \quad * * 0.00 \mathrm{I}<\mathrm{P}<0.01 . \quad * 0.01<\mathrm{P}<0.05$.

From each of the crosses $L_{1} \times H_{1}, L_{1} \times H_{2}, L_{2} \times H_{1}, L_{2} \times H_{2}$, Ioo progeny were isolated. From the crosses $L_{1} \times L_{2}$ and $H_{1} \times H_{2}$ only 50 progeny were isolated as in the original selections. Each set of roo progeny was grown separately in a growth tube experiment, while the two crosses $L_{1} \times L_{2}$ and $H_{1} \times H_{2}$ were randomised together in the same experiment. Each pair of parental monokaryons was also grown in the same experiment as its progeny generation.

\section{(ii) Means, components of variation and the number of effective factors}

The results of these experiments were analysed as previously; the analyses of variance are summarised in table 6 . The components of variation and the mean growth rates of parents and progeny can be found in table 7. Frequency distributions of the growth rates of 
progeny from the crosses between the selection lines are given in fig. 6 , which is drawn on the same scale as figs. 2 and 3 ; here again the differences between the experiments were adjusted according to the $H$ parents. Estimates of the number of segregating effective factors, which were again computed from the ranges of the progeny populations, and also from the parental ranges, are given in table 8.

TABLE 7

Components of variation and means of crosses between selection lines

\begin{tabular}{|c|c|c|c|c|c|c|}
\hline \multicolumn{2}{|c|}{ Parents } & \multirow{2}{*}{$\begin{array}{l}\text { No. of } \\
\text { progeny }\end{array}$} & \multicolumn{2}{|c|}{$\begin{array}{l}\text { Components of } \\
\text { Variation }\end{array}$} & \multicolumn{2}{|c|}{ Mean of growth rates } \\
\hline Monokaryons & $\begin{array}{l}\text { Selection } \\
\text { lines }\end{array}$ & & $V_{E}$ & $V_{G}$ & Progeny & Parents \\
\hline $\begin{array}{l}7444 \times 7454 \\
7418 \times 7664 \\
7649 \times 7454 \\
7647 \times 7664\end{array}$ & $\begin{array}{l}L_{1} \times H_{1} \\
L_{1} \times H_{2} \\
L_{2} \times H_{1} \\
L_{2} \times H_{2}\end{array}$ & $\begin{array}{r}100 \\
99 \\
100 \\
99\end{array}$ & $\begin{array}{r}5 \cdot 721 \\
4 \cdot 913 \\
12 \cdot 327 \\
13 \cdot 853\end{array}$ & $\begin{array}{r}39 \cdot 939 \\
61 \cdot 697 \\
119.944 \\
164.279\end{array}$ & $\begin{array}{l}77 \cdot 2300 \pm 0 \cdot 2236 \\
81 \cdot 1212 \pm 0 \cdot 2228 \\
75 \cdot 7800 \pm 0 \cdot 3508 \\
77 \cdot 3283 \pm 0 \cdot 3^{8} 59\end{array}$ & $\begin{array}{l}76 \cdot 5000 \\
79 \cdot 6250 \\
77 \cdot 2500 \\
77 \cdot 5000\end{array}$ \\
\hline $\begin{array}{l}7444 \times 7647 \\
7454 \times 7664\end{array}$ & $\begin{array}{c}L_{1} \times L_{2} \\
H_{1} \times H_{2} \\
\quad \dagger \dagger\end{array}$ & $\begin{array}{l}49 \\
49 \\
50\end{array}$ & $\begin{array}{l}7.59^{8} \\
1.473 \\
1.49^{\circ}\end{array}$ & $\begin{array}{r}47.078 \\
6.3^{17} \\
18.4^{11}\end{array}$ & $\begin{array}{r}54 \cdot 7449 \pm 0 \cdot 393^{8} \\
100 \cdot 7449 \pm 0 \cdot 1229\end{array}$ & $\begin{array}{r}52 \cdot 0000 \\
101 \cdot 2500\end{array}$ \\
\hline $\begin{array}{l}7418 \times 7444 \\
7647 \times 7649\end{array}$ & $\begin{array}{l}L_{1} \times L_{1} \\
L_{2} \times L_{2}\end{array}$ & $\begin{array}{l}49 \\
46\end{array}$ & $\begin{array}{l}10 \cdot 769 \\
11 \cdot 608\end{array}$ & $\begin{array}{l}20 \cdot 349 \\
20 \cdot 097\end{array}$ & $\begin{array}{l}56 \cdot 6633 \pm 0 \cdot 33^{17} 7 \\
61 \cdot 3370 \pm 0 \cdot 359^{2}\end{array}$ & $\begin{array}{l}56 \cdot 2500 \\
57 \cdot 7500\end{array}$ \\
\hline
\end{tabular}

$\dagger \uparrow$ Alternative analysis including a "variant".

TABLE 8

Two estimates of the number of effective factors, $k$, obtained from the range of parents and progenies of each cross

\begin{tabular}{|c|c|c|c|c|c|c|}
\hline \multicolumn{2}{|c|}{ Parents } & \multirow{2}{*}{$\begin{aligned} & V_{G} \\
= & \widehat{k d^{2}}\end{aligned}$} & \multirow{2}{*}{$\begin{array}{c}\begin{array}{c}\text { Parental } \\
\text { range }\end{array} \\
=2 \hat{k d}\end{array}$} & \multirow{2}{*}{$\hat{k}$} & \multirow{2}{*}{$\begin{array}{c}\begin{array}{c}\text { Progeny } \\
\text { range } \\
\widehat{\widehat{2 k d}}\end{array} \\
=0\end{array}$} & \multirow{2}{*}{$\hat{k}$} \\
\hline Monokaryons & $\begin{array}{l}\text { Selection } \\
\text { lines }\end{array}$ & & & & & \\
\hline $\begin{array}{l}7444 \times 7454 \\
7418 \times 7664 \\
7649 \times 7454 \\
7647 \times 7664\end{array}$ & $\begin{array}{l}L_{1} \times H_{1} \\
L_{1} \times H_{2} \\
L_{2} \times H_{1} \\
L_{2} \times H_{2}\end{array}$ & $\begin{array}{r}39 \cdot 939 \\
61.697 \\
119.944 \\
164.279\end{array}$ & $\begin{array}{l}41 \cdot 00 \\
49 \cdot 75 \\
47 \cdot 50 \\
58 \cdot 00\end{array}$ & $\begin{array}{c}10 \cdot 522 \\
10 \cdot 029 \\
4.703 \\
5 \cdot 119\end{array}$ & $\begin{array}{l}33 \cdot 50 \\
49 \cdot 50 \\
54 \cdot 00 \\
60 \cdot 50\end{array}$ & $\begin{array}{l}7.025 \\
9.929 \\
6.078 \\
5.570\end{array}$ \\
\hline
\end{tabular}

The information revealed by the crosses supports the following points: (i) The differences between $H_{1}$ and $H_{2}$ are small, although significant genetic variation was found among the progeny of the cross $H_{1} \times H_{2}$. One " deviant" similar to others which have been reported earlier was found in this cross. (ii) There are differences between $L_{1}$ and $L_{2}$ which lead to a (significantly) larger $V_{G}$ in the cross between these lines than in crosses within them. (iii) The difference 
between $L_{1}$ and $L_{2}$ is also demonstrated by the magnitude of the $V_{G}$ estimates from crosses with $H_{1}$ and $H_{2}$. Thus the $V_{G}$ estimates were higher in the crosses with $L_{1}$, a fact that is also evident from the spread of the distributions in fig. 6 . (iv) Table 8 shows that in the crosses

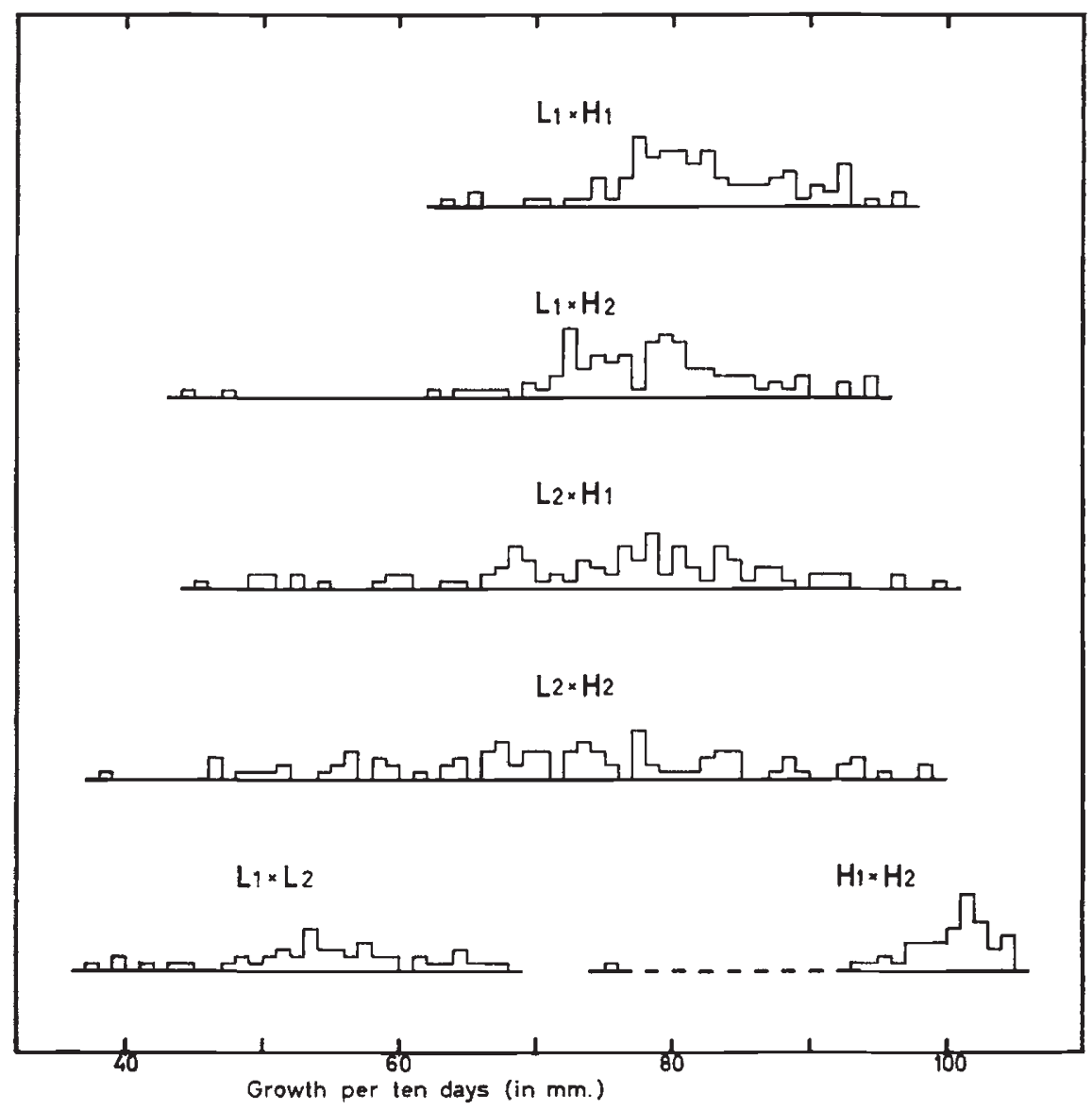

Fic. 6.-Frequency distributions of monokaryotic progenies obtained from crosses between the independent selection lines. The scale is the same as in figs. 2 and 3.

involving $L_{2}$, the estimates of the number of effective factors are lower than in the crosses involving $L_{1}$. This suggests either that polygenes affecting slow growth are spread more evenly over the genome of $L_{1}$, or that fewer such polygenic blocks exist in $L_{2}$, although the effect of each of them is larger than in $L_{1}$. There is of course no clear distinction between the two situations, since the large effect of a polygenic block can be resulted from several "smaller" polygenes that are tightly linked together.

\section{(iii) Linkage relationships}

The mating types of all progeny from crosses between the selection lines were determined, and the linkage of growth rate to the incompatibility factors was tested in the same way as reported earlier. The 
linkage analyses of variance for progeny bearing non-recombinant incompatibility factors are given in table 9. The only difference from the previous tests for linkage was that the probabilities of the $F$ values were halved. The one-tail test of significance was applied since it was known for each cross which of the incompatibility factors was contributed by the $H$ parent, and which one was contributed by the $L$ parent.

TABLE 9

Linkage tests in the analyses of variance of progeny from crosses between selection lines

\begin{tabular}{|c|c|c|c|c|c|c|c|c|}
\hline \multirow{2}{*}{ Monokaryons } & \multirow{2}{*}{$\begin{array}{l}\text { Selection } \\
\text { lines }\end{array}$} & \multirow{2}{*}{$\begin{array}{l}\text { Non-recombinant } \\
\text { progeny }\end{array}$} & \multirow{2}{*}{$\begin{array}{c}\begin{array}{c}\text { Linkage } \\
\text { to } A\end{array} \\
\text { M.S. }\end{array}$} & \multicolumn{3}{|c|}{$\begin{array}{l}\text { Linkage } \\
\text { to } B\end{array}$} & \multicolumn{2}{|c|}{$\begin{array}{l}\text { Genetic } \\
\text { remainder }\end{array}$} \\
\hline & & & & M.S. & $\mathrm{P}$ & $\hat{\sigma}_{L B}^{2}$ & d.f. & M.S. \\
\hline $\begin{array}{l}7444 \times 7454 \\
7418 \times 7664 \\
7649 \times 7454 \\
7647 \times 7664\end{array}$ & $\begin{array}{l}L_{1} \times H_{1} \\
L_{1} \times H_{2} \\
L_{2} \times H_{1} \\
L_{2} \times H_{2}\end{array}$ & $\begin{array}{l}95 \\
96 \\
89 \\
93\end{array}$ & $\begin{array}{r}23 \cdot 74 \\
82 \cdot 73 \\
195 \cdot 31 \\
9.53\end{array}$ & $\begin{array}{l}639 \cdot 52 \\
216 \cdot 15 \\
496 \cdot 40 \\
256 \cdot 35\end{array}$ & $\begin{array}{c}0 \cdot 005-0 \cdot 0005 \\
0 \cdot 15-0 \cdot 10 \\
0 \cdot 10-0 \cdot 05\end{array}$ & $\begin{array}{l}5 \cdot 967 \\
0.885 \\
2.886 \\
0 \cdot 0\end{array}$ & $\begin{array}{l}92 \\
93 \\
86 \\
90\end{array}$ & $\begin{array}{r}83 \cdot 3 \mathrm{I} \\
\mathrm{I} 3 \mathrm{I} \cdot 3^{8} \\
239 \cdot 50 \\
335 \cdot 96\end{array}$ \\
\hline
\end{tabular}

TABLE Io

Means of the mating type groups among the progenies of the crosses between selection lines

\begin{tabular}{|c|c|c|c|c|c|}
\hline \multicolumn{2}{|c|}{ Parents } & \multicolumn{4}{|c|}{ Means of mating type groups } \\
\hline Monokaryons & $H$ & $A_{3} B_{3}$ & $A_{4} B_{3}$ & $A_{3} B_{4}$ & $A_{4} B_{4}$ \\
\hline $\begin{array}{l}7444 \times 7454 \\
7418 \times 7664 \\
7649 \times 7454 \\
7647 \times 7664\end{array}$ & $\begin{array}{l}A_{3} B_{3} \times A_{4} B_{4} \\
A_{4} B_{4} \times A_{3} B_{3} \\
A_{3} B_{3} \times A_{4} B_{4} \\
A_{4} B_{4} \times A_{3} B_{3}\end{array}$ & \begin{tabular}{|}
$74 \cdot 3056 \pm 0 \cdot 4057$ \\
$83 \cdot 5000 \pm 0 \cdot 2959$ \\
$73 \cdot 5600 \pm 0 \cdot 5130$ \\
$80 \cdot 4792 \pm 0 \cdot 4986$
\end{tabular} & $\begin{array}{l}76 \cdot 486 \pm \pm 0 \cdot 2869 \\
80 \cdot 4048 \pm 0 \cdot 3477 \\
73 \cdot 3500 \pm 0 \cdot 5736 \\
77 \cdot 4000 \pm 0 \cdot 4886\end{array}$ & $\begin{array}{l}78 \cdot 8269 \pm 0 \cdot 3375 \\
79 \cdot 6875 \pm 0 \cdot 3253 \\
74 \cdot 7272 \pm 0 \cdot 5469 \\
75 \cdot 6400 \pm 0 \cdot 4886\end{array}$ & $\begin{array}{l}80 \cdot 5667 \pm 0 \cdot 4444 \\
80 \cdot 5000 \pm 0 \cdot 3397 \\
78 \cdot 8409 \pm 0 \cdot 5469 \\
77 \cdot 7632 \pm 0 \cdot 5604\end{array}$ \\
\hline
\end{tabular}

Only in one cross, that is $L_{1} \times H_{1}$, could linkage to the $B$ factor be demonstrated. When, however, the mean growth rates of the four incompatibility groups were calculated, they showed higher growth rates for the groups containing the $B$ factors from the $H$ parents (table 10). Since our test of linkage is very much affected by the remaining genetic variance, it is understandable why such linkage relationship could only be demonstrated in the cross with the lowest genetic variance $\left(V_{G}\right)$. Estimates of the components of variation due to linkage to $B$ were, nevertheless, calculated for all four crosses, and they are also included in table 9. Although the significant and semisignificant linkages were found in crosses with $H_{1}$, it is difficult to accept that they are due to an allele at a linked locus which is present in the $H_{1}$ and not in the $H_{2}$ selection line, since in the $H_{1} \times H_{2}$ cross, there was no evidence for difference at loci linked to the incompatibility factors. 
An attempt was also made to test linkage of polygenic blocks to other chromosomal markers. Eleven resistance mutations to Neomycin sulphate (400 mg./1.) were induced by u.v. irradiation in members of the $H_{2-6}$ generations. However, no linkage could be demonstrated when 40 progeny were examined from a cross between one of these mutants and a compatible monokaryon from $L_{2-5}$.

\section{DISCUSSION}

The experiments reported here illustrate the considerable genetic variation existing among progeny of single wild isolates. As in Collybia velutipes (Croft and Simchen, 1965), the growth rate of monokaryotic mycelia of $S$. commune appears to be under the control of a polygenic system. However, when this system is compared between the two fungi, some differences become apparent. In general, the $V_{G}$ estimates for the Collybia isolates are larger than those for Schizophyllum; that is to say, there is more heterozygosity in the former at loci controlling monokaryotic growth rate than in the latter. At the same time the range of growth rates is wider in Collybia and therefore the estimates of the number of effective factors, $k$, are similar in both fungi. One should remember, however, that by estimating $k$ an assumption was made that the $k$ effective factors have all equal effect, $d$, of which the range and $\sqrt{V_{G}}$ are both linear functions. There is therefore a marked difference in the magnitude of $d$ between the polygenic systems controlling monokaryotic growth in $S$. commune and $C$. velutipes. The genetical units (effective factors or polygenic blocks) are larger in effect in Collybia, and in two of the seven isolates of this fungus, even major genes affecting growth rate were found to segregate $\left(M_{1}-m_{1}\right.$ and $\left.M_{2}-m_{2}\right)$. It is possible that the greater genetic variation recovered in $C$. velutipes reflects the more important role of the monokaryotic phase in its life cycle. Once a monokaryon of $S$. commune meets a compatible mycelium, a stable dikaryon is formed and the monokaryotic phase is therefore relatively short. In $C$. velutipes, however, where dedikaryotisation occurs, the monokaryotic phase is prolonged and can derive secondarily from the dikaryotic mycelium; variation for monokaryotic characters in this fungus will probably have more of an adaptive role.

A more precise definition of an effective factor or a polygenic block can be achieved by mapping such factors in the formal linkage map, as it was done for loci determining the number of sternopleural chaetæ in Drosophila melanogaster (Thoday, 196r). The linkage between growth rate and the $A$ incompatibility factor, which was established for three of the four American isolates (table 3) defines one of the effective factors for growth rate fairly well. It is proposed here to call the polygenic block which has been found to be linked to the $A$ incompatibility factor in $S$. commune the " $L A$ gene ". Similarly, the polygenic block which was found to be linked to the $B$ factor among progeny 
of crosses between the selection lines will be designated the " $L B$ gene". The significance of the linkage mean squares in the analysis of variance, as well as the relative magnitude of the linkage components of variation, is, however, conditioned by heterozygosity of the linked locus, and depends on the magnitude of the linked locus relative to that of all loci which are affecting the character. Furthermore, it is also dependent on the frequency of recombination between the linked locus and the incompatibility factor. The agreement between the estimates of $k$ and the proportion of $V_{G}$ that the " $L A$ gene" is responsible for, and the fact that the distribution of growth rates is not bimodal, suggest that the linkage to the $A$ factor is quite tight, at least in isolates 5 and 6 . Whether heterozygosity for " $L A$ " is characteristic of the American isolates and whether the " $L A$ genes" are identical in isolates 3,5 and 6 has not yet been established. The linkage between the " $L B$ gene" and the $B$ incompatibility factor, which was detected among progeny resulting from crosses between $H$ and $L$ selection, is probably looser than the previous linkage relationship. This linkage could not be demonstrated in the original sets of progeny obtained from isolate 2 (see table 3). It is plausible therefore that the " $L B$ gene" was built up during the course of the selection by crossover changes from the repulsion to the coupling phase.

We have seen that the heritable variation which was found to exist among monokaryotypic progeny of wild isolates of $S$. commune provided a considerable response to the selection pressure imposed upon it. Moreover, a response occurred in both directions, towards high as well as towards low growth rate, and the selection lines even went beyond the range of the original population from which they were started (that is progeny of isolate 2). The range of progenies from crosses between $H$ and $L$ lnies was almost as wide as the range between the selection lines themselves, and much wider than the range of progeny from the original dikaryon (compare fig. 6 with figs. I, 2 and 3 ). The heritable component of variation, $V_{G}$, changed also considerably, increasing from 28.87 (the mean of experiments $2(a)$ and $2(b)$ ) to 50.82 (mean of crosses with $L_{1}$ ) and 142.11 (mean of crosses with $L_{2}$ ). Changes in the genetic variation during selection experiments can be either due to fixation of certain alleles resulting from the selection and the inbreeding or due to changes in linkage relationships between different elements of the polygenic system. Fixation of certain alleles in the selection lines can only bring about a decrease in $V_{G}$, when the progenies of crosses between such lines are compared with the original population, or-when for every locus two different alleles are fixed in the two selection lines which are due to be crossed-to no change in $V_{G}$. The observed increase in the heritable variation can therefore only be due to changes in the linkage relationships from repulsion $(+-,-+)$ to coupling $(++,--)$. Let us assume a simplified model, where $k$ genes are present, each with an effect $d$, arranged in $k / 2$ linked pairs with recombination frequency 
of $p$ within the pairs and independent reassortment between them. The haploid progeny of the repulsion heterozygote (where for every pair of linked genes the situation is $\frac{+-}{-+}$ ) will have a variance of $[2 p]^{k / 2} k d^{2}$, while the variance of the coupling heterozygote $(\underline{+}+$ for every pair of linked genes) will be $[2(\mathrm{I}-p)]^{k / 2} k d^{2}$. When no linkage exists in the system $\left(p=\frac{1}{2}\right)$, these two variances reduce of course to $k d^{2}$, which is the expectation given earlier (page 244). Thus a change from repulsion linkage to coupling brings about an increase in the heritable variation of the resulting population, providing that in most loci alleles are not eliminated by inbreeding and selection. The $V_{G}$ estimates obtained here mean that in our experiments, the selection process consisted not only of rearrangement of independent loci in the associated form, but also of recombination of loci and changes of tight linkage relationships from the repulsion (or opposing) phase to the coupling (or reinforcing) phase. This is comparable to the results achieved by selection in Drosophila melanogaster (Mather and Harrison, I949; Thoday and Boam, 196I).

Although the selection for growth rate succeeded in both directions, it showed definite signs of asymmetry. In the first 3-4 generations, the selection was already more effective downwards, but this is probably due to unequal selection pressures, as the response during this period was directly related to the selection differential (see fig. 4). The $H$ lines had reached by then their selection limits, and later became homozygous (i.e. homokaryotic for growth rate genes in the dikaryotic phase). At this stage the response in the $L$ selections was very slow in spite of the apparent high genetic variation. Thus the heritable variation, estimated by $V_{G}$, did not respond in the same manner in both directions: it was eliminated by the selection and inbreeding only in the two $H$ selections (fig. 5). The difference between the $H$ and $L$ selections in respect of the $V_{E}$ estimates is probably connected with the previous aspect of asymmetry; they will therefore be considered simultaneously.

Falconer ( 1960 ) has summarised the possible causes for asymmetrical response to selection and for selection limits. Naturally, Falconer is concerned with diploid organisms, and therefore his most important factors cannot be applied to our selection results. Thus directional dominance, selection of heterozygotes and inbreeding depression are not very relevant to haploid organisms, while directional gene frequencies and maternal effects are not likely to be important since most generations were raised from one dikaryon each. This leaves us with scale effects, which usually bring about a faster response in the $H$ selections and not in the $L$ selections, and with undirectional natural selection, which could not account for the haploid phenomena observed here. 
The asymmetry in the selection experiments in $S$. commune must be explained therefore on other genetic mechanisms. Two such mechanisms, unidirectional non-additive interaction and the instability of certain genotypes, will be discussed in some detail. Both are probably quite important in haploid polygenic systems, although they are by no means restricted to such systems, and may provide explanations of asymmetries in selection experiments with diploid plants and animals.

Unidirectional interaction was found to be a characteristic of the polygenic systems for resistance to chloramphenicol in the bacterium Escherichia coli (Cavalli and Maccacaro, 1952). When two independent selections, obtained by successive transfers through increasing concentrations of the drug, were crossed, the progeny showed a general breakdown of the resistance. The levels of resistance of the progeny varied from very low up to the high parental levels, but very seldom did they exceed the parental resistance. This non-additive situation was an outcome of the method used for selecting these polygenic systems. Thus a mutation for chloramphenicol-resistance was favoured if it increased the level of resistance existing already, and therefore only the first mutation in each system was selected to act on its own; all the other mutations were selected to act in the presence of the preceding resistance mutations. As a result of genetic segregation, these late-stage mutations were separated from the genes with which they were selected to interact and the progeny showed less resistance than expected.

A similar situation appears to exist in Aspergillus nidulans (Jinks, Caten, Simchen and Croft, I966) where it was shown that in crosses between isolates from different heterokaryon-compatibility groups, almost all the progeny grew slower than the two parents. Thus growth rate in $A$. nidulans was selected for independently in the different compatibility groups, each polygenic system being probably built by successive mutations for fast growth, superimposed on the system already controlling growth. Whether this process of natural selection acted upon asexual progeny (conidia or mycelial sectors) similar to Cavalli and Maccacaro's experiments with $E$. coli, or whether it acted on sexual progeny (ascospores), is not of much importance because A. nidulans, as a homothallic fungus, produces mainly "selfed " progeny.

Such unidirectional interaction could perhaps provide an explanation of the different selection limits which were arrived at in the experiments with $S$. commune; the asymmetry in the estimates of the heritable variation $\left(V_{G}\right)$ might also be attributed to such interactions. One would expect, however, that in crosses between $H$ and $L$ selection lines, the mean of the progeny would be lower than the mean of the parental growth rates, as Cavalli and Maccacaro (1952) found when they crossed chloramphenicol-resistant strains with sensitive strains of $E$. coli. In the crosses between the selection lines reported above, such deviation of progeny means from parental means could not be demonstrated (table 7), and therefore unidirectional non-additive interaction 
in the polygenic system controlling monokaryotic growth in $S$. commune has not been proved.

We have demonstrated, that when grown in the same experiments, the $L$ selections always provided higher $V_{E}$ estimates than the $H$ selections. Since one expects comparisons of $V_{E}$ within experiments to be relative measures of stability, it appears that certain genotypes (the $H$ lines) are more stable than others (the $L$ lines). A similar situation existed in our original assessment of variation among monokaryotic progeny of wild isolates, where isolates 4 and 6 gave much higher $V_{E}$ estimates than the other four isolates (table 2). These high $V_{E}$ 's reflect the pattern of mycelial growth, as irregularity in growth and the appearance of sectors have been observed in many growth tubes inoculated with $L$ monokaryons or with progeny of isolates 4 and 6.

That stability changes can develop in the course of selection and inbreeding has been demonstrated by Mather (1953) and Thoday (1955, 1958) for asymmetry in the number of sternopleural chaetæ of Drosophila melanogaster. In these experiments the developmental instability was the property of the selected genotypes and not of the homozygosity per se, as the instability was shown by Thoday (1958) to persist when two such unstable lines were crossed. The instability could have developed in the selection lines either by breakdown of balanced complexes which control stability and the formation of new " unstable" complexes (Mather, 1953), or by direct selection of genes for instability through the extreme phenotypes, which were due to those instability genes and not to extreme genotypes of the selected character (Falconer and Robertson, 1956). Selection of unstable genes could also be indirect, through linkage to the selected polygenic system controlling the character, or even through pleiotropy; the latter hypothesis is, of course, a compromise between the two former ones. It is rather difficult to allocate one of these explanations to the results of our experiments, although selected instability-directly or indirectly -is more plausible, since both $L$ selection lines developed, independently higher $V_{E}$ values than the $H$ lines.

The persistently high $V_{G}$ estimates of the $L$ selections could be attributed to heavy " masking " of the desired genotypes by the high instability, or to susceptibility of the $L$ genotypes to environmental effects in the early stages of the young mycelia, which persist during later growth. An hypothesis assuming such defects in the "canalisation" system of monokaryotic mycelia of $S$. commune is supported by the fact that certain monokaryons that do not accept migrating nuclei of compatible strains (unilateral dikaryotisation) will do so readily if mated very young, as germinating basidospores (Parag, 1962).

A cytoplasmic explanation for the asymmetry in the $V_{E}$ estimates will not hold without also postulating a strong interaction with certain nuclear genotypes. We should have to postulate that unstable cytoplasms have an effect on growth only when present in the same cells 
as nuclei of the $L$ selections, and have no effect on monokaryons of the $H$ selections. Alternatively, it may be postulated that an unstable cytoplasm could only be selected when associated with slow growing nuclei, and that the $H$ lines have an unselected, stable cytoplasm. This latter explanation will hold, for example, if an unstable cytoplasm could only decrease the growth rate, and therefore would have been selected for only in the $L$ selection lines.

\section{SUMMARY}

Considerable variation of growth rate was found to exist among monokaryotic progenies of six wild isolates of $S$. commune. Estimates of the heritable and non-heritable components of this variation, and subsequently of the number of effective factors segregating, were obtained.

Selection for high and low growth rates of monokaryons was carried out with progeny of one of the isolates. Two high lines $(H)$ and two low lines $(L)$ were selected for in nine successive generations. The $H$ selection lines reached their selection limits and homozygosity while the $L$ lines maintained high heritable variation and showed a greater divergence from the parental mean. The $L$ selection lines also maintained higher environmental variance than the $H$ lines, although grown in the same experiments. The duplicate selections behaved very similarly during the course of the selection.

Crosses between the selection lines showed very high genetic variances, which suggested that recombination had an important role in the response to selection.

Linkage of a polygenic block affecting growth rate to the $A$ incompatibility factor was established in three of the original wild isolates. Loose linkage of another polygenic block to the $B$ incompatibility factor was postulated among the progenies of crosses between the selection lines, although demonstrated with confidence in only one of four crosses.

Acknowledgments.-I wish to thank Professor J. L. Jinks and Dr J. H. Croft for their advice and encouragement throughout the course of this work and during the preparation of the manuscript for publication. I am also indebted to Professor J. R. Raper for sending me the fruit bodies from which dikaryons $3,4,5$ and 6 were isolated.

Part of this work was undertaken while in receipt of the Rosalind Franklin Grant from the Friends of the Hebrew University of Jerusalem, London, N.W.1, to whom I am very grateful.

\section{REFERENCES}

CAVAlli, L. L., AND MacCACARo, G. A. 1952. Polygenic inheritance of drug-resistance in the bacterium Escherichia coli. Heredity, 6, $31 \mathrm{I}-33 \mathrm{I}$.

CROFT, J. H., AND SIMCHEN, G. 1965. Natural variation among monokaryons of Collybia velutipes. Amer. Naturalist, 99, 453-464.

FALCONER, D. s. 1960. Introduction to Quantitative Genetics. Oliver \& Boyd, Edinburgh and London. 
FALCONER, D. S., AND ROBERTSON, A. 1956. Selection for environmental variability of body size in mice. Z. indukt. Abstamm. $u$ Vererb., $87,385-391$.

JiNks, J. L., CATEN, C. E., SIMChEN, G., AND CROFT, J. H. 1966. Heterokaryon incompatibility and variation in wild populations of Aspergillus nidulans. Heredity, 2I, 227-239.

MATHER, K. I953. Genetical control of stability in development, Heredity, 7, 297$33^{6}$.

MATHER, x., AND harrison, B. J. 1949. The manifold effect of selection. Heredity, $3,1-52,131-162$.

Papazian, H. P. 1950. Physiology of the incompatibility factors of Schizophyllum commune. Bot. Gaz., II2, 143-163.

PAPAZIAN, H. P. 195 I. The incompatibility factors and a related gene in Schizophyllum commune. Genetics, $36,44 \mathrm{I}-459$.

PARAG, Y. 1962. Mutations in the B incompatibility factor in Schizophyllum commune. Proc. Nat. Acad. Sci., 48, 743-750.

RAPER, J. R., BAXTER, M. G., AND MIDDLETON, R. B. J958. The genetic structure of the incompatibility factors in Schizophyllum commune. Proc. Nat. Acad. Sci., 44, 889-900.

RAPER, J. R., AND MILES, P. G. 1958. The genetics of Schizophyllum commune. Genetics. $43,530-546$.

SIMChEN, G., AND JiNKs, J. L. 1964. The determination of dikaryotic growth rate in the basidiomycete Schizophyllum commune: a biometrical analysis. Heredit), Ig, 629-649.

SNEDECOR, G. W. 1956. Statistical Methods ( $5^{\text {th }}$ edition). Iowa State University Press, Ames.

SNIDER, P. J., AND RAPER, J. R. 1958. Nuclear migration in the basidiomycete Schizophyllum commune. Amer. F. Bot., 45, 538-546.

THODAY, J. M. 1955. Balance, heterozygosity and developmental stability. Cold Spr. Hrbr. Symp. Quant. Biol., 2o, 318-326.

THODAY, J. M. 1958. Homeostasis in a selection experiment. Heredity, 12, 40I-4I 5. THODAY, J. M. I961. Location of polygenes. Nature, I9I, 368-370.

THODAY, J. M., AND BOAM, T. B. I96r. Regular responses to selection. I. Description of responses. Genet. Res., 2, 161-1 76 . 